\title{
Evaluation of an e-learning device for workers' compulsory training: an example of collaboration between university and company
}

\author{
Floriana Falcinelli ${ }^{\mathrm{a}}$, Marco Gatti ${ }^{\mathrm{b}}$, Francesco Claudio Ugolini ${ }^{\mathrm{c}}$, Serena Sabatini ${ }^{\mathrm{d}}$ \\ ${ }^{a}$ University of Perugia, Italy, floriana.falcinelli@unipg.it,0000-0003-2906-6356 \\ ${ }^{b}$ Consorzio Interprovinciale di Servizi - Coop, Italy, marco.gatti@cis.coop.it \\ 'University Guglielmo Marconi, Italy,f.ugolini@unimarconi.it,0000-0002-7887-7983 \\ ${ }^{d}$ Consorzio Interprovinciale di Servizi - Coop, Italy, serena.sabatini@cis.coop.it
}

\begin{abstract}
In this article, we present the collaboration between the Quality, Hygiene, Security and Training department of the service provider of the Coop-branded cooperatives and the Human Sciences and Education Department of the University of Perugia, the objective of which was compulsory training in the fields of Job Security and Food Hygiene, provided by the company in e-learning, and addressing the employees of several cooperatives operating in the largescale organised distribution sector.

The collaboration contemplates two steps. The first one consisted of the certification of compliance according to certain quality criteria. Course evaluation and certification were therefore assigned to an external institution that researches these subjects and thus was able to provide the training governance team with matter for reflection on the implemented training path, also indicating some potential aspects that needed to be further developed. The second step consisted of a wide-ranging, articulated empirical research that, on the one hand, enabled the university to cast light on a phenomenon that has been studied little or not at all from an educational viewpoint and, on the other, has enabled the Consorzio Interprovinciale di Servizi-Quality, Hygiene, Security and Training department (CIS-QuISF) to enhance its professional perspective and the e-learning mode to gain increasing recognition.
\end{abstract}

Keywords: e-learning, compulsory education, evaluation, quality of education

\section{Introduction $^{1}$}

In this article, we present the collaboration between the Quality, Hygiene, Security and Training department (QuISF) of the service provider Consorzio Interprovinciale di Servizi (CIS) of the Coop branded cooperatives (Cooperative di consumo a marchio Coop) and the Human Sciences and Education Department (Dipartimento di Scienze Umane e della Formazione, then Dipartimento di Filosofia, Scienze Sociali, Umane e della Formazione) of the University of Perugia. The objective of this collaboration was compulsory training in the fields of Job Security (Sicurezza nei luoghi di lavoro) and Food Hygiene (Igiene degli Alimenti), provided by the CIS-QuISF in the e-learning mode, and addressing the employees of several cooperatives, operating in the large-scale organised distribution (Grande Distribuzione Organizzata $-G D O$ ) sector, whose size and territorial location are different and heterogeneous.

This collaboration contemplated two steps: the certification of compliance according to certain quality criteria (this phase is described in Section 1) and the implementation of evaluation research on the didactical device in terms of quality in education and training. This research is briefly described in the second section. Against the framework of this special issue of this journal, the aim of this article is to present an instance of how university research can contribute to business development, rather than the research itself; an in-depth description of this latter can be found in a previous research report (Falcinelli, Gatti \& Ugolini, 2014a)².

\footnotetext{
${ }^{1}$ The author of Introduction section and Section 1 is Floriana Falcinelli. The authors of Section 2 and Section 3 are Francesco C. Ugolini and Serena Sabatini, respectively. The author of Section 4 is Marco Gatti.[AU: Please check the edits to the footnotes carefully.]

${ }^{2} \mathrm{~A}$ synthesis of the research results can also be found in a previous study (Falcinelli, Gatti \& Ugolini, 2014b). For details about use and evaluation of e-learning systems in the context of vocational training, see other related articles (Attwell, 2006; Ehlers \& Pawlowski, 2006; Galliani, 2000, 2004; Galliani \& Costa, 2003; Ghislandi \& Raffaghelli, 2013; Ghislandi, Pedroni, Pellegrini \& Franceschini, 2008; Nacamulli, 2003; Trentin, 1998, 1999a, 1999b, 2008; Trinchero, 2002b).
} 


\section{Evaluation of an e-learning device for workers' compulsory training: an example of collaboration between university and company \\ Falcinelli, Gatti, Ugolini, Sabatini}

With this aim, we report the company ${ }^{3}$ viewpoint in the last two sections: in the third section, Serena Sabatini describes the effects of the collaboration with the University on the organisation and professionalisation of the QuISF Department, while in the fourth, the head of the QuISF offers the overall conclusions on this experience.

\section{First step: evaluation of the educational efficacy of the compulsory e-learning courses}

The collaboration between CIS and the University of Perugia started in 2010. CIS approached the University Department of Human and Educational Sciences (Scienze Umane e della Formazione) to validate the compulsory education e-learning courses from an educational viewpoint.

The University Department therefore analysed the learning course structure and organisation. We used a model inspired by the areas of analysis indicated by the CERFAD guidelines (2000). This choice was made considering that the CERFAD Commission developed these quality criteria guidelines for the certification of distance education learning materials that responded well to the mainly erogative nature of the compulsory training paths we examine. Their structure was actually based on rather strict regional norms with regard to the use of distance education in compulsory training.

Those areas were as follows:

- Resource area: a) human Resources and their competences; b) learning materials; c) technical infrastructure

- Process area: a) needs analysis - recruitment; b) orientation; c) general design, media use, learning materials/resources, support system and the subsystems involved; d) execution of the course/learning experience; e) assessment and meta-assessment

- Context area: we examined specifically the following dimensions: the specific environment (institutional/legislative), the organisation (internal resources), the inter-organisational environment (external resources), the users, the user-learner organisation and/or specific environment, resources and constraints

Starting from those areas, the guidelines proposed specific criteria, each one of them with its own description and focus points, highlighting how each of them interacts with the others. On this basis, the Department drew up a certification of duration and conformity, regarding the complete distance education courses, ascertaining the presence of the following elements:

- The human resources employed in the content development process and in the course delivery and maintenance are competent and expert in their sector;

- The course design matches the intermediate and final learning objectives, which are measurable and fulfilled the European, Italian and regional regulations, in terms of job security and food hygiene;

- The course design provides the planning of intermediate and final tests, which are useful also in learner selfevaluation;

- The course materials lead to a learning certification;

- There is a help and support system to assist the learners during the course;

- The learning content is presented in a language that integrates written and spoken text, images and sound; the information mode is correct, clear and comprehensible, in addition to being both adequate for the receivers' characteristics and widely usable even to those who do not have a high level of information and communications technology (ICT) exposure;

- The learning content is well structured in an organic way and in a satisfactory logical sequence;

- The learning content is consistent with the declared learning objectives and with the recipients' expectations;

- Traceability and retention of the online activities is constantly granted, so that the learner is able to resume his/her learning path from the very point he/she reached in his/her previous working session, in addition to being able to monitor his/her learning path constantly;

- The course complies with the Sharable Content Object Reference Model (SCORM) 1.2 standards.

We also faced the problematic issue of the "standard duration" of an e-learning course. We chose to adopt the "timeequivalent" approach (Istituto per lo Sviluppo della Formazione Professionale dei Lavoratori [ISFOL], 2003, pp. 71-72) as the best approach from a didactical viewpoint: in an e-learning course, indeed, learners and teachers interact in an asynchronous way; moreover, each learner follows his/her course at his/her own pace and, furthermore, an e-learning device consists of several tools and methods that are integrated one with another, within the same learning environment. Determining a standard face-to-face duration corresponding to the same learning objectives is actually not that difficult in this case, as the compulsory training courses are numerous and are highly standardised.

We think it is important to point out that course evaluation and certification were assigned to an external institution, which researched these subjects and therefore was able to provide the training governance team with matter for reflection on the implemented training path, indicating also some potential aspects that needed to be further developed.

${ }^{3} \mathrm{CIS}$ is a particular type of company, as it is both a consortium of cooperative companies and a cooperative company itself. It provides technical, legal and administrative services to the cooperatives associated with it (refer ciscoop.it for details). As it provides compulsory training services through the QuISF department, it also acts as a training agency (Agenzia formativa), acknowledged as such by the Tuscany Region. In this article, however, we will refer to it as the "Company", as a counterbalance to the University within the collaboration we are describing here. 


\section{Evaluation of an e-learning device for workers' compulsory training: an example of collaboration between university and company \\ Falcinelli, Gatti, Ugolini, Sabatini}

Those issues actually provided the motivation for starting a research course, which enabled trainers and researchers to govern the whole process better.

\section{Second step: evaluation research}

The collaboration between the University of Perugia and the CIS-QuISF has been enriched by a further step since 2012: an evaluation research aimed at evaluating the e-learning device in terms of quality in education and training. This research benefitted from the huge amount of data stored within the CIS information system and was also integrated with interviews with the people in charge of compulsory training in the cooperatives using the e-learning courses - the cooperatives actually were the "customers" of the CIS - and with a survey to the end users, who were the workers who took part in the courses.

From a methodological viewpoint, the research followed three principles.

- It was an evaluation research of idiographic nature (Coggi \& Ricchiardi, 2005; Trinchero, 2002a); according to Keegan, indeed, "when the management of quasi-industrial processes ${ }^{4}$ is central to an educational system, what is needed is not normative scientific study of special approaches to pedagogy but problem-based case studies that can provide guides to good practice" (Keegan, 1993, p. 15).

- According to Galliani (2000), within a broader concept of quality in education and training, the quality of service, the quality of instruction and the quality of education strictu sensu should be treated separately; the research addressed mainly the quality of service and, to a lesser extent, the quality of instruction (in reporting some information linked to the achievement of the courses).

- With respect to the quality of service, the research adopted the two main approaches: the compliance approach and the customer satisfaction approach (Conti, 2010); the former was mainly addressed during the first step of the collaboration (refer Section 1), while the latter was specifically the objective of the second step that we describe.

According to these principles, we conducted the research adopting a multimethod approach within an idiographic perspective ${ }^{5}$, using the following data collection tools:

- An in-depth analysis of the data from the two CIS information systems (the management system and the Moodle one, which was more linked to the learning process);

- Interviews with those in charge of compulsory training in the cooperatives that used the CIS e-learning service; these were semi-structured standardised open-ended interviews (Patton, 1980; Cohen, Manion \& Morrison, 2007 , p. 353) when the cooperatives were of small or medium size, while they were non-structured, following a guide approach (ibidem) when the cooperatives were of a bigger size;

- A survey, using a structured questionnaire, addressed to the workers taking part in the courses.

All three of them contribute to outlining a detailed picture on how e-learning could be a fruitful solution in a context that is complex and heterogeneous, as the cooperatives organisation may vary substantially in size (and, therefore, by internal organisation $)^{6}$ and in territorial location, and the laws regulating the compulsory training on job security and food hygiene show some differences from region to region. One of the aims of the research was actually to understand how e-learning could address this heterogeneity. Moreover, as many workers already followed similar courses in a classroom-based mode ${ }^{7}$, we could ask both the persons in charge of compulsory training (via interview), and the workers (via questionnaire) which mode they prefer.

We summarise here the main results of the research, while we refer to the full report (Falcinelli, Gatti \& Ugolini, 2015a) for a more complete description of the sources of data, the data themselves and how such data support our conclusions.

- From 2010 to 2014 , CIS dispensed almost 17,000 e-learning courses ${ }^{8}$ that were followed by more than 7,000 employees, operating in 624 different workplaces all over Italy. This huge amount would have caused many difficulties if those courses were to be organised in the classroom mode.

- Almost all the employees passed the test on their first try, scoring, on average, from 17 to 18 good answers out of 20 .

- One of the most interesting issues we found was the different ways in which the courses were followed depending on the cooperative size:

\footnotetext{
${ }^{4}$ In the early years of distance education, in the second half of the 20th century, the industrialisation in distance education was an issue, especially studied by Otto Peters (1973). More recently, the scientific literature prefers to speak of "organisational dimension" of distance education and elearning (Sidir \& Cochard, 2004; Ugolini, 2015).

${ }^{5}$ The triangulation of methods is one feature of the idiographic research (Trinchero, 2002a, p. 84).

${ }^{6}$ The range spreads from a two-employee, single-shop cooperative to some having more than 8,000 employees and more than 100 sales points, also varying in size.

${ }^{7}$ The compulsory training must be updated on a regular basis, depending on the specific regulation.

${ }^{8}$ From May 27th 2010 to July 26th 2014 CIS dispensed 16,867 courses. From then on, CIS dispensed almost 13,000 more courses. We must point out that every employee may have followed more than one course (more than half of them actually did it).
} 


\section{Evaluation of an e-learning device for workers' compulsory training: an example of collaboration between university and company \\ Falcinelli, Gatti, Ugolini, Sabatini}

- The small-sized cooperatives took advantage of the higher flexibility made possible by e-learning courses; these employees followed their courses in several stages: in the smallest cooperatives, only half of them ended the course the same day they started it. This happens because these cooperatives typically consist of only one sales point ${ }^{9}$, with only one or two workers overall, and therefore, organising a specific session on compulsory training presents many problems.

- The bigger-sized cooperatives prefer to organise specific sessions, as bigger sales points are able to schedule their employees' absences for training. Such organisation varies from cooperative to cooperative, but we noticed that the bigger the cooperative, the higher is the percentage of workers who complete their course the same day they started it.

- The persons in charge of compulsory training noticed that there are two main advantages of the e-learning mode: first, the employees paid greater attention to the e-learning course than they did in the classroom mode ${ }^{10}$; and second, there was individualisation of the learning process ${ }^{11}$. A few of them also indicated the multimedia feature of the learning materials.

- The main problems noticed by both the persons in charge and the workers were those of a technical kind. These were particularly inconvenient for the older workers (almost one in seven was older than 50 years). Some of the interviewees highlighted the lack of interaction with the teacher, though the bigger-sized cooperatives usually did not completely eliminate the classroom mode; apart from training reasons, they also wished to retain contact between the central administration and the workers of the different sales points.

- Both the persons in charge and the workers prefer the e-learning mode over the classroom-based one. The former are especially favorable to e-learning when the cooperative is small or medium sized (only two answerers out of 33 preferred the classroom-based mode). When the size of the cooperative grew, the answers became more articulate: the e-learning mode is still preferable from an educational viewpoint, but many respondents pointed out that the classroom mode can be profitable as people are enabled to meet one each other, on the one hand, allowing the governance to maintain contact with their workers and, on the other, enabling the workers themselves coming from different workplaces to exchange views about their working practices. However, we must say that the bigger-sized cooperatives usually run further classroom-based training in addition to the compulsory one, and some of them keep a part of the training in a classroom mode. As for the workers, more than half of the respondents to the questionnaire showed a preference for the e-learning mode (38.3\% showed a strong preference for the e-learning mode), while only $27 \%$ preferred the classroom-based one. Many of them belong to an older age group: we can, therefore, conclude also on the basis of some free answers to an open-ended question that the reasons for this preference were mostly of a technical kind.

- The persons in charge overall are satisfied with the CIS courses in e-learning mode. Some referring to the bigger-sized cooperatives are nonetheless more analytic regarding the points that can be improved. As for the workers, they show in majority a "good" satisfaction. Even if only $17.4 \%$ of them expressed an unsatisfactory or a satisfactory evaluation, we must also say that only $27.7 \%$ expressed a "very good" or an "excellent" satisfaction. Considering the preference towards the e-learning mode described earlier, we think that perhaps the overall judgement concerning compulsory training influenced such evaluation.

From the point of view of knowledge acquired, due to wide-ranging, articulated empirical material and the data available regarding a great number of subjects, this research cast light on a phenomenon - compulsory training - that has been studied little or not at all from an educational viewpoint. In fact, we observed that in this area, where educational repercussions can only be limited, the e-learning mode turned out to be an appropriate solution, not only in dealing with important management and organisational issues ${ }^{12}$ but also from a didactical viewpoint, as described herein. With regard to these aspects, we can say that e-learning has been adopted in order to improve the quality of learning (European Commission, 2001) in this specific field.

In the next two sections, we will present the other point of view, that of CIS-QuISF. First, Serena Sabatini, after nine years' experience in the department, will bear witness to the major changes that have occurred in the organisational management due to the collaboration with the University. And then, finally, the head of QuISF, Marco Gatti, will offer some overall reflections on this experience.

\footnotetext{
${ }^{9}$ Punto di vendita. The word "outlet" in Italy is commonly used to indicate the outlet stores where manufacturers sell their stock directly to the public. Therefore, we adopt here the more literal translation "sales point".

${ }^{10}$ We report a significant excerpt from an interview: "I think that the employees are more concentrated [in Distance Education mode] than they were in the classroom. It may appear like a great utopia but I actually realized that in an 8-hour long classroom session the workers learned half with respect to the response they give in Distance Education mode".

${ }^{11}$ We report a significant excerpt from another interview: "[there is] more elasticity in managing time. Being 8 hours in a classroom can be hard for people who are not used to it. [In distance education mode] they have a different approach to training, in terms of time managing".

${ }^{12}$ We must recall that the compulsory training has to be periodically updated.
} 


\section{Evaluation of an e-learning device for workers' compulsory training: an example of collaboration between university and company \\ Falcinelli, Gatti, Ugolini, Sabatini}

\section{Impact of the collaboration with the University on the QuISF department's organisational growth}

The CIS-QuISF (Quality, Hygiene, Security and Training) department, as it deals with the Food Hygiene and Job Security issues, has already been overwhelmingly involved in vocational training since the late nineties, while the regulations of the EU and within Italy were evolving. Driven by the need to make the compulsory training system sustainable in both economic and organisational terms, our working team launched the e-learning challenge in 2007.

Within a context occupied by network structures of sales points widely varying in size and dispersed all over the place yet having a centralised support, in theory, distance education responded perfectly to our needs as it shortens physical and temporal distances while increasing management flexibility.

An educational device with a hand-crafted feel to it came into being, designed and developed using internal resources that were neither specified by time-location nor purpose-made according to educational and professional backgrounds. It was actually a bet on ourselves, a team of young people challenging themselves with a simplified approach, the "rapid e-learning" approach ${ }^{13}$. We used tools to build learning objects that were imported onto a Moodlebased learning management system (LMS) platform, which - over the years - has undergone many customisations, and has been implemented making use of external professionals.

We can today state that we won that bet. The professional growth of the QuISF Department as an e-learning service provider was long and we believe it is still continuing, but the turning point, the quantum leap can be easily identified, as it began with recognition in the research analysis carried out by the University of Perugia. The awareness of the work we have done, of the value of our training device and of the aims we have reached has been one of the motivational impulses that moved our educational structure from its initial hand-crafted feel to a professional status.

Today, e-learning is a part of our core business and it is managed with in-house professionals acquired ad hoc. Moodle has been progressively replaced by new functionalities integrated in Aladino software. The latter has reached version 6.0, and it has been fully implemented and managed by an ICT internal technician. We abandoned the "rapid elearning" approach in favour of a custom-made developing mode being realised by our multimedia and graphic developers, bringing huge improvements in how courses can be used and endless possibilities for graphic solutions and interactions. This choice permitted us to improve both course design and usability. The extreme compression of the elements allowed, in addition to an increase of speed in fruition, the adoption, in the division of the learning units, of criteria based only on pedagogical needs, rather than technical ones ${ }^{14}$.

\section{Overall considerations from the company perspective}

The idea of interacting with the University arose from the need to go beyond a self-referencing logic in producing learning objects to achieving a more exacting, binding one: external certification.

Since 2007, in the compulsory training field, e-learning (or what passed for e-learning) had the air of low-cost, lowranking training, aimed only at achieving the certifying "rubber stamp", given that the discriminating factor, i.e. the training needs of the individual, was limited to the "presence/absence" of the certificate.

Not for us. Right from the beginning, when e-learning was hardly more than an experiment, with little knowledge, few resources and plenty of good will, we determined to offer our associates something more than a "rubber stamp".

The experience, first with the Florentine University and immediately after with the University of Perugia, drew the attention of our associates to the added value our learning objects received from such collaboration in terms of sustainability in the eyes of the inspecting authority. Such training was actually a legal requirement, and any breach is still subjected to sanctions both under administrative (Reg. CE 852/2004) and criminal (D.lgs. 81/08 e s.m.i.) norms.

What we asked the University to do was essentially to verify that the following objectives were satisfied:

- The learning materials were coherent with the course objectives;

- The learning objects matched the SCORM standards;

- The standard course duration was confirmed, with a classroom time-equivalent approach.

What the University gave us was much more than this! Not only did it satisfy our needs, it also stimulated our curiosity to verify, check and compare. And that was what we did.

We had several instances of interchange: first, a life cycle assessment (LCA) study carried out with the University of Florence, then an article in a publication regarding the eco-sustainability of materials and technologies (Gatti, 2014) and, finally, the actual study itself of the whole structure with the publication of the full research report (Falcinelli, Gatti, \& Ugolini, 2015a).

The publication of this volume and the findings contained in it consolidated and demonstrated the winning formula of the training system so far implemented, albeit in a hand-crafted fashion. We were thus enabled to operate an in-depth internal reflection on the future of this activity.

\footnotetext{
13“Rapid e-learning" defines a methodology, assisted by specific editing software, aimed at producing and delivering learning materials at low cost and with reduced development time.

${ }^{14}$ The user is now able to launch the course from the dashboard and complete it in the same web page, without, for instance, having to refresh it in order to unlock the following unit or to change the pop-up settings in the web browser.
} 


\section{Evaluation of an e-learning device for workers' compulsory training: an example of collaboration between university and company \\ Falcinelli, Gatti, Ugolini, Sabatini}

It seems that a premise on the issue is due: e-learning training conflicted, and to some extent today still conflicts, with the norms regulating compulsory training, i.e. regional deliberations and agreements within the State-Regions Conference. It was actually an arduous, step-by-step task to bypass those norms in order to convince the relevant regional offices to grant us permission to supply such training in e-learning mode. This was achieved by first presenting a detailed project, in which collaboration with the University and the link between our work and the University experts stood out clearly. I am convinced that it was this link that significantly contributed to the approval of the projects.

From the other viewpoint - the user viewpoint - the publication of this volume and the approval by the Region of our e-learning-based device helped to decrease the front of the skeptics so much that, from 16,867 courses provided during the period 2010-2014 (July), we provided 13,537 more courses during the period from 2014 (August) to 2016 (September). This means moving from an average of 192 to an average of 541 courses/month.

Further evidence on the extent to which this academic study influenced the choices made within the structure is the transition from a "hand-crafted" approach - in which everyone did everything - to a professional approach, with the recruitment in our workforce of people specialised in multimedia graphics and ICT.

So, as Director of the Training Agency, I can only be proud of undertaking this path, with the determination to maintain and, if possible, expand it. We hope, however, that this will promote the start of an opinion trend that will see the University becoming a super partes evaluation body. The validation it provides, while giving added value to learning objects, should effectively be recognised and turned into score, within the evaluation of merit- or fundingoriented processes, just as happens for a UNI/International Organization for Standardization (ISO) certification.

The introduction of a UNI-like standard for e-learning certification would certainly provide quality enhancement for e-learning in general, that same e-learning so often perceived as being second or third rate. Such certification would call the courses produced by their real name, so as to offer consumers a clear and rational choice, thereby marginalising any "wiliness" in the e-learning offer.

\section{References}

Attwell, G. (2006). Evaluating e-learning. A guide to the evaluation of e-learning, Evaluate Europe Handbook Series Vol. 2.

CERFAD (2000). Guida alla qualità dei servizi di erogazione e supporto della formazione a distanza. Bologna: CERFAD - Regione Emilia Romagna.

Coggi, C., \& Ricchiardi, P. (2005). Progettare la ricerca empirica in educazione. Roma: Carocci.

Cohen, L., Manion, L., \& Morrison, K. (2007). Research Methods in Education (sixth edition). New York: Routledge.

Conti, T. (2010). Storia della qualità. In M. Sartor, \& V. Mazzaro (Eds.), Qualità. La gestione, gli strumenti, le best practice. Dall'industria alle società di servizi, alla pubblica amministrazione (pp. 3-23). Milano: Sole24Ore.

Ehlers, U.-D., \& Pawlowski, J.M. (2006), Handbook on quality and standardisation in E-Learning. BerlinHeidelberg: Springer.

European Commission (2001). The eLearning Action Plan. Designing tomorrow's education. Retrieved from eurlex.europa.eu/legal-content/EN/TXT/PDF/?uri=CELEX:52001DC0172\&from=EN

Falcinelli, F., Gatti, M., \& Ugolini, F. C. (Eds.) (2015a). E-learning e obbligo formativo dei lavoratori. Valutazione di un dispositivo didattico nella Grande Distribuzione Organizzata: il caso del Consorzio Interprovinciale di Servizi nel sistema Coop. Lecce-Brescia: Pensa Multimedia.

Falcinelli, F., Gatti, M., \& Ugolini, F.C. (2015b). La formazione obbligatoria in e-learning nella Grande Distribuzione Organizzata. Una ricerca s,ul campo. In M. Rui, L. Messina, \& T. Minerva, Teach Different! Proceedings della multiconferenza EMEMITALIA2015 (pp. 107-110). Genova: Genova University Press.

Galliani, L. (2000). Ricerca valutativa e qualità nella formazione, Studium Educationis, 2, 350-371.

Galliani, L. (2004) (Ed.). Formazione in rete. Indicatori di qualità e buone pratiche. Napoli: Tecnodid.

Galliani, L., \& Costa, R. (2003). Valutare l'e-learning. Lecce-Brescia: Pensa Multimedia.

Ghislandi, P.M.M., Pedroni, A., Pellegrini, A., \& Franceschini, D. (2008). eLearning e qualità. iGeL Il Giornale dell'eLearning, 2(3).

Ghislandi, P.M.M., \& Raffaghelli, J. (2013). Per una cultura di qualità: valutazione partecipata e apertura di contenuti generati dagli utenti nella didattica online. Formazione \& Insegnamento, 11 (2), 87-102.

Gatti, M. (2014). La certificazione di qualità nella formazione professionale a distanza: da un'idea a una realtà. In M. Ciani Scarnicchi, A. Laino, P. Pinelli, \& A. Romani, Materiali e tecnologie ecosostenibili come nuove opportunità (pp. 225-232). Roma: Aracne.

ISFOL (2003). La qualità dell'e-learning nella formazione continua. Roma: ISFOL. Retrieved from europalavoro.lavoro.gov.it/EuropaLavoro/Varie/La-qualit-dellelearning-nella-formazione-continua-.

Keegan, D. (1993). Foundation of Distance Education. London: Routledge.

Nacamulli, R.C.D. (Ed.) (2003). La formazione, il cemento e la rete. E-learning, management delle conoscenze e processi di sviluppo organizzativo. Milano: ETAS.

Patton, M.Q. (1980). Qualitative Evaluation and Research Methods (second edition). London: Sage. 


\section{Evaluation of an e-learning device for workers' compulsory training: an example of collaboration between university and company \\ Falcinelli, Gatti, Ugolini, Sabatini}

Peters O. (1973). Die didaktische Struktur der Fernunterrichts. Untersuchungen zu einer industrialiserten Form des Lehrens ybd Lerens. Weinheim: Beltz.

Sidir M., \& Cochard G.-M. (2004). Méthodes et outils de gestion en e-formation. In I. Saleh, \& S. Bouyahi (Eds.), Enseignement à distance: épistémologie et usages (pp. 93-114). Paris: Hermès-Lavoisier.

Trentin, G. (1998). Insegnare e apprendere in rete. Bologna: Zanichelli.

Trentin, G. (1999a). Telematica e formazione a distanza. Il caso Polaris. Milano: Franco Angeli.

Trentin, G. (1999b). Qualità nella formazione a distanza. Una analisi del rapporto fra qualità, interattività e costi nella formazione a distanza. TD - Tecnologie Didattiche, 16 (1).

Trentin, G. (2008). La sostenibilità didattico-formativa dell'e-learning. Milano: Franco Angeli.

Trinchero, R. (2002a). Manuale di ricerca educativa. Milano: Franco Angeli.

Trinchero, R. (2002b). Valutazione della qualità della formazione on line. In C. Coggi, A. Notti (Eds.), Docimologia (pp. 275-287). Lecce-Brescia: Pensa Multimedia.

Ugolini, F.C. (2015). The organizational dimension of distance education. Historical, pedagogical and policy aspects. Pedagogia Oggi, 2/2015, 213-222. 